\title{
Projeto Catadores de Sonhos
}

\section{Project Catadores de Sonhos}

\author{
CORRÊA, Glaucinei Rodrigues; Doutorado; UFMG \\ glaucinei@ufmg.br \\ VIANA, Anamaria Fernandes; Doutorado; UFMG \\ anamariafernandes160@gmail.com
}

\section{Resumo}

Este artigo apresenta o Projeto Catadores de Sonhos: design e dança para o bem-estar social, o qual desenvolve ações com o objetivo de melhorar a condição socioeconômica de catadores da Associação dos Catadores de Papel, Papelão e Material Reaproveitável (Asmare), localizada em Belo Horizonte. Os procedimentos metodológicos utilizados tiveram a participação ativa de catadores, alunos bolsistas e voluntários na concepção e integração dos métodos e instrumentos envolvidos em todas as atividades. O projeto teve como norte a proximidade entre os sujeitos, uma relação dialógica, concebida com base no respeito e no reconhecimento mútuo. Como contribuições destacam-se as diversas reflexões para as áreas do Design e da Dança e as perspectivas de trabalhos futuros, a partir de uma melhor compreensão dos grupos envolvidos e da própria instituição. Tal compreensão se dá por meio de um maior entendimento da complexidade das ações do projeto oriunda das condições de vida e de trabalho próprias a essas pessoas e que, muitas vezes, extrapolam as áreas do Design e da Dança.

Palavras Chave: catadores; design; dança.

\begin{abstract}
This article presents the Project Catadores de Sonhos: design and dance for social welfare, which develops actions aimed at improving the socioeconomic status of Asmare waste pickers. The methodological procedures used had the active participation of the collectors, scholarship students and volunteers in the conception and integration of methods and instruments that involved all the activities. The project had as its northern objective the proximity between the subjects, a dialogical relationship, conceived by respect and mutual recognition. As contributions we highlight the various reflections for the areas of Design and Dance and perspectives of future works from a better understanding of the groups involved and the institution itself. This understanding comes through a greater understanding of the complexity of the project's actions derived from the living and working conditions proper to these people and that often extrapolate the areas of Design and Dance.
\end{abstract}

Keywords: collectors; design; dance. 


\section{Introdução}

O Projeto Catadores de Sonhos: design e dança para o bem-estar social ${ }^{1}$, promovido em parceria com a Associação dos Catadores de Papel, Papelão e Material Reaproveitável (Asmare) desde 2014, tem por objetivo principal melhorar a condição socioeconômica dos catadores associados. Surgiu a partir de uma demanda da própria associação em ter produtos próprios, os quais pudessem ser produzidos e comercializados para se tornarem fonte de renda alternativa à catação.

A Asmare, fundada em 1990, surgiu em função do trabalho de mobilização e capacitação dos catadores, realizado pela Pastoral de Rua da Arquidiocese de Belo Horizonte, fruto de um intenso processo mobilizatório. Atende diretamente 180 associados e ex-moradores de rua em duas unidades (denominadas "galpões"), as quais apresentam diferenças tanto de infraestrutura quanto de relação dos associados / catadores com a instituição. $O$ galpão principal que é maior, situa-se na região central de Belo Horizonte, na Avenida do Contorno, o qual recebe o material trazido pelos próprios catadores das ruas, que possuem pequenos espaços onde cada um realiza a triagem do próprio material e vende para a associação ao final da semana. Nele, há uma marcenaria, que era utilizada para a manutenção dos carrinhos dos catadores, a qual estava desativada na época do desenvolvimento desse projeto. O segundo galpão que se localiza mais afastado do Centro, na Rua Ituiutaba, recebe, principalmente, materiais em grande escala, vindos da prefeitura, por meio da coleta seletiva e de doações de empresas. Os catadores que lá trabalham realizam a triagem, sendo o lucro ao final dividido igualmente entre eles no final de semana.

Ao longo desses anos, diversas ações e atividades foram desenvolvidas com alunos do curso de Design e, desde 2017, também com alunos do Curso de Licenciatura em Dança da UFMG. A seguir, faz-se um breve histórico das ações e atividades realizadas.

Em 2014, o projeto foi realizado com apoio financeiro da Pró-reitoria de Extensão da UFMG, mediante a concessão de bolsas a três alunos. Desenvolveram-se soluções para um serviço prestado pela Asmare, denominado "Evento Sustentável", que consiste na gestão de resíduos para grandes eventos. Foram desenvolvidos os projetos para a marca, para os uniformes e para os coletores utilizados durante a prestação do serviço (CORRÊA et al, 2015).

Em 2015 e 2016, o projeto recebeu o apoio financeiro do Ministério da Educação, mediante a concessão de bolsas para sete alunos e de recursos para custeio e capital. Foram desenvolvidos produtos para serem produzidos e comercializados pelos próprios catadores, para que pudessem ter uma fonte de renda alternativa à catação. Além disso, houve o desenvolvimento e a implantação do site para a Asmare $^{2}$ (CORRÊA et al, 2017).

A última fase do projeto, de agosto de 2017 a junho de 2018, teve apoio das Pró-reitorias de Extensão e de Graduação da UFMG, mediante a concessão de bolsas a dois alunos, um do Design e outro da Dança.

A continuidade deste projeto se fez necessária pelas seguintes razões:

\footnotetext{
${ }^{1}$ Mais informações no site do projeto: www.arq.ufmg.br/catadores.

${ }^{2}$ Ver: <www.asmare.org>.
} 
a) Parte das ações anteriores não foi concluída, por exemplo, capacitação dos associados em relação às noções básicas de desenvolvimento de produtos, em função de problemas internos da Asmare e do atraso no repasse de recursos aprovados pelo Ministério da Educação. Dessa forma, a continuidade garantiria que essas ações fossem executadas.

b) Desejo de desenvolver mais produtos, explorando, por exemplo, materiais diferentes daqueles desenvolvidos nos primeiros produtos (feitos em madeira) nos anos anteriores. Neste caso, um dos materiais seria a lona, que é recebida em grande quantidade e com a qual os associados não conseguem gerar renda.

c) Necessidade de trabalhar melhor a autoestima dos associados. Este foi um dos principais entraves relacionados ao atraso das atividades, o qual comprometeu, de certa forma, os resultados. Por essa razão, nesta última etapa do projeto foram inseridas atividades relacionadas à dança, as quais visaram construir um espaço de escuta no qual cada liberdade criativa teve sua vez e pode se desenvolver plenamente. Participaram do projeto uma professora, também cocoordenadora, e uma aluna do Curso de Licenciatura em Dança da UFMG.

As atividades deste projeto foram divididas em duas ações paralelas: oficinas de dança (desenvolvimento da memória e do repertório de movimento); e oficinas de design (desenvolvimento e fabricação de produtos na marcenaria).

\section{Fundamentação teórica}

A relação que norteou as atividades do projeto fundou-se na proximidade entre os sujeitos, uma relação dialógica, baseada no respeito e no reconhecimento mútuo. Nas atividades do projeto, procurou-se valorizar as pessoas e, principalmente, compreender o desenvolvimento das ações e atividades com (e não para) os catadores / associados.

A Pesquisa-ação foi utilizada como referência para o planejamento e a construção de parte das ações. De acordo com Thiollent (1986), trata-se de um tipo de pesquisa social com base empírica, concebida e realizada em estreita associação com uma ação ou com a resolução de um problema coletivo, no qual os pesquisadores e os participantes representativos da situação ou problema estão envolvidos de modo cooperativo ou participativo.

Professores, alunos, catadores e membros da comunidade trocavam entre si seus saberes e descobertas, aprendendo uns com os outros. Esse processo rompeu a relação tradicional, em que o professor, ou mestre, apenas ensina e o aluno apenas aprende. Lidamos com a ideia de aprendizagem de Lave e Packer (2008), ou seja, de que estamos sempre aprendendo e que não dependemos de um local específico para que a aprendizagem ocorra. Segundo Lave e Wenger (1991), sempre quando pensamos na aprendizagem, o primeiro aspecto que cogitamos é a relação mestre-aprendiz. Mas, na prática, os papéis do mestre são surpreendentemente variáveis no tempo e no espaço, e essa relação mestre-aprendiz não é uma característica definidora da aprendizagem.

Neste projeto, sejamos professores ou estudantes responsáveis por uma oficina, temos que manter a vigilância desse "lugar do saber", pois, ao impor o que pensamos conhecer, empobrecemos a própria possibilidade de conhecimento. Privamos o sujeito diante de nós de nos ensinar e o privamos também de outras perspectivas, já que "existe inteligência lá onde cada 
pessoa age" (RANCIÈRE, 1987, p. 56, tradução nossa). A criação de espaços nos quais a pessoa desenvolve sua autoestima é fundamental para o fomento do seu saber e da troca de saberes.

Rancière declara que "todos os homens têm uma inteligência igual" (RANCIÈRE, 1987, p. 34, tradução nossa). E a leitura que fazemos dessas palavras, extraída da experiência de Jean Joseph Jacotot $^{3}$ (1770-1840), é que todos nós, em nossas diferenças, estamos sempre nos completando com os outros.

Para criar esses espaços e construir a partir desse território que o outro nos oferta, é preciso, também, um mínimo de curiosidade, a curiosidade "da diferença do outro", sem a qual não construímos, não criamos, mas colocamos, decretamos. Paulo Freire nos ensina que "o exercício da curiosidade convoca a imaginação, a intuição, as emoções, a capacidade de conjecturar, de comparar, na busca da perfilização do objeto ou do achado de sua razão de ser" (FREIRE, 2002, p. 52).

Para Strauss (1992, p. 39), a dança provoca uma dilatação do espaço do corporal que pode ser vivido pelo indivíduo "[...] como enriquecimento ou como uma ameaça". Essa ameaça, que impede o abandono do sujeito ao movimento dançante, já pode nascer no que Godard (2002) chama de "pré-movimento", a dança antes do seu acontecimento, da sua aparição. Ainda de acordo com Strauss (op. cit.), é por causa do sentimento de ameaça que o indivíduo é incapaz de produzir um movimento expressivo, já que a dança "investe de maneira direta a relação entre o sentir e o movimento" (citado por GÉLY, 2014, tradução nossa).

O espaço dançante que estamos criando é aquele que elogia a singularidade de cada um, que cultiva a confiança e o não julgamento, um espaço no qual cada pessoa pode desenvolver suas potencialidades criativas e expressivas. A dança transforma, acolhe as diferenças (a sua e a do outro) e dá nascimento a novos campos estéticos. Salienta Louppe (2004):

A dança, a coreografia, não nos ensina apenas a dividir o espaço, mas também a conhecêlo e a aceitá-lo. O espaço do outro e o nosso, com todas as falhas simbólicas, às quais só a dança pode dar sentido. Elas nos ensinam a dilatar o espaço, torná-lo palpável, torná-lo legível (p. 186, tradução nossa).

De modo geral, o projeto teve como característica principal a indissociabilidade entre ensino, pesquisa e extensão, o que provocou impacto positivo na formação dos estudantes, pela geração de conhecimento e pela relação dialógica com a sociedade, à medida que os alunos colocaram em prática o aprendido na Escola. Assim, as atividades do projeto geraram ganhos técnicos-sociais e pessoais para os estudantes ao longo da interação com os catadores.

\section{Procedimentos metodológicos}

Os procedimentos metodológicos utilizados tiveram como direcionamento a participação ativa dos associados da Asmare, dos alunos bolsistas e dos colaboradores convidados, em ações

\footnotetext{
${ }^{3}$ Joseph Jacotot foi professor da Universidade de Louvain no século XIX. Ele pediu a seus alunos que não sabiam Francês que estudassem sozinhos a língua, por meio de uma edição bilingüe de Fénelon. Pelo estudo do texto e de sua tradução, e sem qualquer explicação do mestre, os estudantes se mostraram capazes de apreender o funcionamento de construção de frases em francês e contar nessa língua o que tinham compreendido do romance. Essa experiência o conduziu a propor um método de ensino capaz de promover a capacidade de aprender por si mesmo, ao invés do método clássico de transferência do saber entre mestre e estudante.
} 
que envolveram todo o projeto. Nessa perspectiva, as etapas desenvolvidas ao longo do projeto foram:

Etapa 1 - Capacitação dos alunos para o trabalho com a comunidade e para lidar com esse tipo de público-alvo: pessoas excluídas, de alguma forma, da sociedade. Houve a necessidade de, em primeiro lugar, promover um treinamento capaz de esclarecer as formas e as maneiras de lidar com o grupo. O objetivo foi preparar os alunos de modo a elucidar quem eram essas pessoas, quais eram os possíveis problemas que iriam enfrentar e, principalmente, quais eram os modos para lidar com a situação.

Etapa 2 - Realização de estudos e pesquisas sobre grupos e instituições no Brasil e no mundo que lidam com esse tipo de atividade. Teve como meta pesquisar o estado da arte em relação às associações e outros tipos de organizações que desenvolvem trabalhos semelhantes ao da Asmare.

Etapa 3 - Preparação do material didático para o projeto: os alunos prepararam o material a ser utilizado na capacitação dos associados da Asmare, o qual abordava temas que os ajudaram a entender melhor o funcionamento do projeto, predefinidos com a diretoria da associação e, depois, com os envolvidos no projeto: conceitos relacionados ao design, ao artesanato e ao mercado; criatividade e desenvolvimento de produto; tendências de comportamento e linhas de produto; estudo da cor e da forma; propriedades e processos dos materiais; e embalagem. Os recursos para essas atividades abarcaram aulas expositivas e oficinas práticas.

Etapa 4 - Capacitação dos associados da Asmare para o desenvolvimento de produtos. Previa a preparação dos catadores envolvidos no projeto para que pudessem ter uma noção do desenvolvimento de produtos e, assim, pudessem contribuir e participar ativamente de todo o processo.

Etapa 5 - Desenvolvimento dos produtos, marcas e embalagens, juntamente com os catadores / associados. Incluiu todo o desenvolvimento dos produtos. Os alunos puderam experimentar e colocar em prática o que estavam aprendendo em sala de aula. Além disso, tiveram o compromisso de envolver os associados no desenvolvimento dos produtos.

Etapa 6 - Divulgação dos resultados (processos e produtos desenvolvidos) alcançados com o projeto. Consistiu na elaboração de artigos e no lançamento do livro Catadores de Sonhos: design em projetos de extensão ${ }^{4}$, no qual se divulga todo o desenvolvimento dos projetos, de 2014 a 2017. O livro também relata a trajetória de luta e conquistas da Asmare, descreve aspectos da história e da política da extensão universitária da UFMG, aborda os programas e projetos de extensão da Escola de Arquitetura, fornece informações a respeito do curso de graduação em Design na UFMG e reflete sobre as Diretrizes Nacionais de Extensão.

Para retomar o projeto em 2017, reuniões foram realizadas com os catadores dos dois galpões: uma reunião geral com o pessoal que trabalha na Rua Ituiutaba e outra com os associados da Avenida do Contorno. Em ambas, apresentaram-se e discutiram-se com os presentes: o projeto de continuidade, a importância das ações propostas, as oficinas de dança e as oficinas de design. Além disso, expuseram-se os resultados das etapas anteriores (site da Asmare e produtos desenvolvidos) que alguns desconheciam.

\footnotetext{
${ }^{4} \mathrm{O}$ livro pode ser adquirido no site do projeto: www.arq.ufmg.br/catadores.
} 
Os associados da Rua Ituiutaba ficaram mais interessados pela oficina de dança e os da Avenida do Contorno, pela oficina de design.

De acordo com os comentários e as manifestações das pessoas que participaram dessas reuniões, ficou combinado que na semana seguinte teriam início a oficina de dança no galpão da Rua Ituiutaba, e a oficina de design, no galpão da Avenida do Contorno.

Figura 1 - Reunião com os associados da Asmare da Av. do Contorno

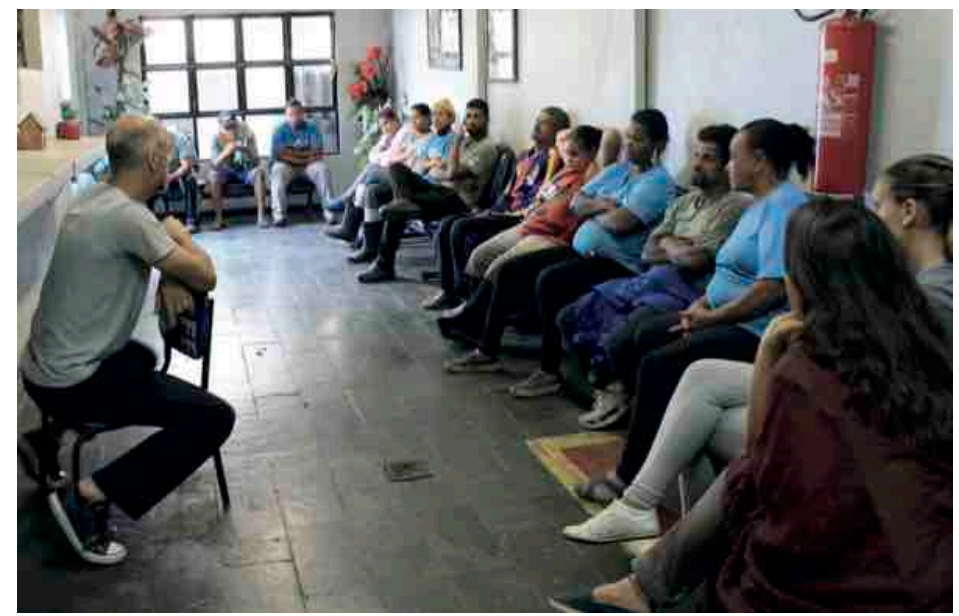

Fonte: Autores

\subsection{As oficinas de dança}

Relatou a dançarina e professora de dança Anamaria Fernandes Viana, cocoordenadora deste projeto:

Quando o corpo se expressa através do movimento poético sem qualquer forma de preconceito, ele se torna linguagem e expressão para si, para o outro e para o grupo. Torna-se um veículo de comunicação, um território de encontro consigo mesmo que permite a interação com o outro e a criação de uma outra espacialidade para esse corpo, tomando como eixo principal o desenvolvimento da riqueza que constituem a diferença e a singularidade de cada um (Informação verbal).

Os objetivos principais da oficina de dança foram: a) desenvolver a consciência do corpo, do corpo em movimento, do corpo no espaço e do corpo em relação uns com os outros; b) gerar, promover e desenvolver a criatividade e as potencialidades próprias de cada indivíduo; c) fornecer os meios possíveis para criar um espaço comum em que todos possam ser protagonistas; d) favorecer o bem-estar e incentivar a confiança e a autoestima; e) valorizar a presença e o compromisso; f) possibilitar um outro olhar sobre si mesmo e sobre o outro; e g) promover o encontro e as trocas para formar um grupo que acolha as diferenças do outro.

Os encontros eram realizados semanalmente, atendendo às demandas dos associados. 0 grupo era composto por nove mulheres. O conteúdo das aulas abrangia temáticas variadas, incluindo ritmos, técnicas e dinâmicas de grupo.

Esse trabalho foi desafiador, uma vez que a demanda de cada semana e as participações ocorreram de maneira instável. Nem todas as pessoas presentes em uma semana estavam 
disponíveis na próxima, e vice-versa. Ressaltam-se dois outros desafios encontrados: primeiro, propor atividades de baixo grau de dificuldade, por conta das especificidades do grupo, mas que, ao mesmo tempo, poderiam ser motivadoras e fazer com que percebessem a evolução ao longo dos encontros; e segundo, fazer a desconstrução gradativa da ideia da dança puramente técnica, realizada por cópia e repetição. Assim, buscou-se oferecer possibilidades de vivências que envolvessem a consciência corporal e a ludicidade, para o desenvolvimento de suas potencialidades criativas, visando estimular a autoconfiança das participantes, que, sem dúvida, têm um grande potencial.

De outro lado, o interesse que as participantes demonstraram em realizar as diferentes propostas constituiu-se na maior motivação para dar continuidade ao trabalho. Elas questionavam, tentavam realizar as atividades, davam sugestões e participavam ativamente durante a oficina.

Até março de 2018, essas oficinas foram ofertadas na sala de alimentação do local de trabalho das participantes, o que gerou diferentes dificuldades para sua realização. Diante disso, foi firmada uma parceria com o músico Maurício Tizumba, responsável pelo espaço Tambor Mineiro, local onde foram iniciadas as oficinas a partir de abril de 2018.

Figura 2 - Oficina de Dança na Asmare da Rua Ituiutaba

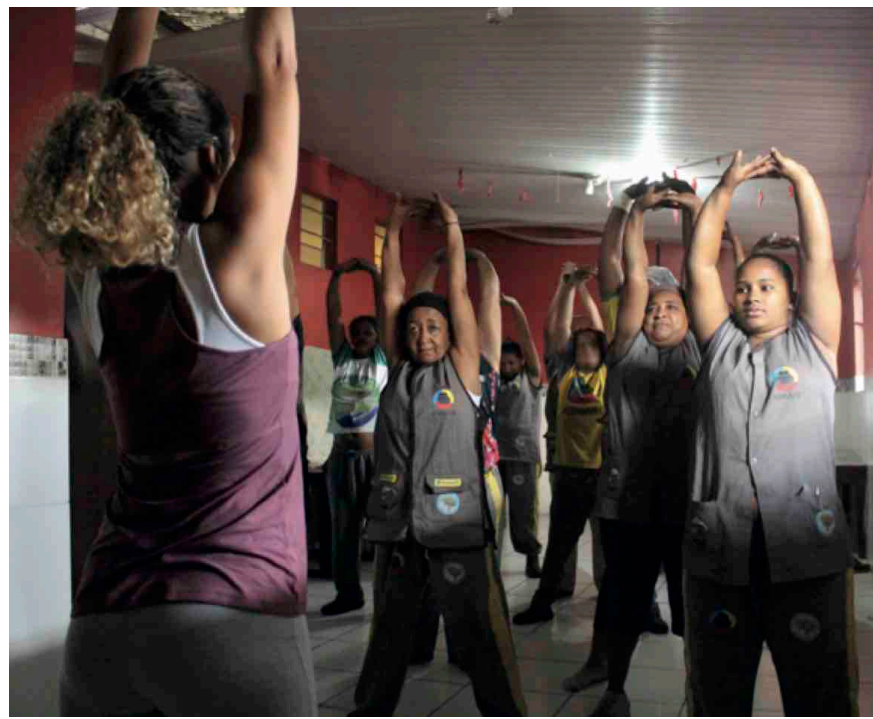

Fonte: Autores

\subsection{As oficinas de design}

Essas oficinas tiveram por objetivo principal capacitar os interessados no trabalho de marcenaria com os produtos desenvolvidos nas etapas anteriores do projeto.

Antes de começar o projeto, havia uma proposta de lidarmos com alguns temas durante as oficinas para que esse trabalho de produção pudesse ser feito. Além disso, em vez de somente fabricar os produtos, nossa meta sempre foi capacitá-los para que pudessem participar do processo de projeto. Nesse sentido, antes de começarmos com a "mão na massa", prevíamos 
algumas oficinas que pudessem dar suporte às atividades de desenvolvimento de projeto.

No início, havia sete pessoas interessadas: três catadores e quatro jovens filhos de catadores. Uma primeira reunião foi realizada com eles para explicar nossa proposta e para ouvir deles as expectativas em relação às oficinas. De acordo com o perfil dos interessados, resolvemos começar a oficina pelo desenho. O desenho é uma ferramenta fundamental para o projeto, tanto para o desenvolvimento de propostas como para a apresentação dos produtos, além de ser essencial para direcionar a fabricação.

Na primeira oficina de desenho, como previsto, o número de interessados diminuiu e se restringiu a um grupo de três pessoas: um associado e dois filhos de catadores. Apresentamos como seria o módulo de desenho e entregamos a eles uma pasta com um caderno de desenho, lápis e borracha. Explicamos que, em um primeiro momento, as oficinas se fundamentariam em um nível básico, para que todos pudessem desenvolver seus traços, entender sobre a desconstrução de desenhos e compreender o desenho como um conjunto de elementos, e não só uma figura complexa.

Figura 3 - Oficina de Design na Asmare da Av. do Contorno

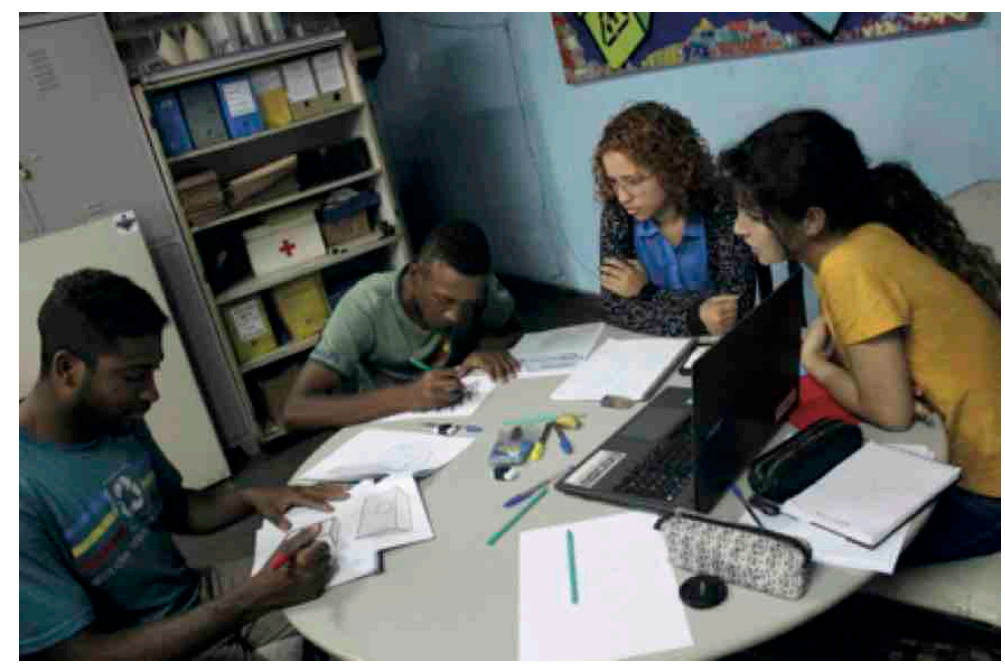

Fonte: Autores

Encontramos pelo caminho dificuldades para mantê-los interessados pela oficina e para encorajá-los a praticar em casa as atividades de desenho. Planejamos as oficinas, contextualizando-as com projetos feitos na marcenaria, como, luminárias, brinquedos e objetos de decoração, demonstrando a eles, com fotos e vídeos, o grau de importância das oficinas de desenho como base para o desenvolvimento de produtos. Além disso, entregamos apostilas curtas, com exercícios rápidos e objetivos, para serem feitos diariamente até o dia da oficina seguinte.

Com o baixo índice de participação e a partir de conversas com os participantes dessa oficina, percebemos que uma nova abordagem possivelmente daria mais motivação a eles. Assim, decidimos em conjunto (re)iniciar a oficina de design, dessa vez começando por atividades na marcenaria. 
No momento de finalização deste artigo, estávamos discutindo com os associados a melhor maneira de darmos prosseguimento às atividades do projeto e, consequentemente, de retomar as atividades na marcenaria.

\section{Resultados e discussão}

De maneira geral, pode-se concluir que grande parte dos objetivos foi abarcada, apesar das dificuldades encontradas e das mudanças ocorridas ao longo do desenvolvimento das atividades. Desde o início, sabia-se que não seria fácil e que surgiriam muitos desafios, em função da complexidade das ações, da quantidade de pessoas envolvidas e, principalmente, da peculiaridade da forma de atuação da associação, voltada para a valorização das pessoas em detrimento da parte comercial.

De certo modo, vários dos desafios foram superados, levando-se em consideração a relação dialógica entre os envolvidos. Tal prática ajudou a encontrar alternativas viáveis para todos os problemas ao longo da execução do projeto.

Ao final, surgiram dificuldades para a fabricação dos produtos e, consequentemente, para fazer o acompanhamento de sua comercialização. Primeiro, porque as atividades principais da associação envolvem a catação e a triagem. Portanto, para os catadores acrescentarem qualquer outra atividade seria necessário um processo lento de mudança. Segundo, para implantar um projeto, leva-se tempo, e, como houve atraso nas atividades, não houve esse tempo para fazer o acompanhamento da parte comercial.

A partir disso, pode-se refletir sobre alguns aspectos que, de alguma maneira, podem contribuir com as áreas de conhecimento do Design e da Dança na relação com grupos e instituições envolvidos, como no caso deste projeto.

Primeiro, é preciso entender a instituição (ou grupo) em seu contexto, ou seja: as atividades que ela exerce, as pessoas que estão envolvidas, como é o dia a dia e, os entraves, sobretudo, os principais problemas relacionados ao contexto ou mercado no qual atua. No caso da Asmare, a peculiaridade está em sua forma de atuação, que valoriza e acolhe pessoas em situação de rua e ex-detentos em detrimento dos aspectos comerciais. Essa maneira de lidar com as pessoas e com a sociedade faz com que a associação se diferencie das demais associações de catadores, porque lida com outros valores, os quais vão muito além dos comerciais - por exemplo, a valorização da vida e o respeito às pessoas. Nesse caso, ter entendido esse aspecto fez toda a diferença no andamento das atividades, bem como nos resultados alcançados com o projeto de modo geral.

Outro aspecto importante é o entendimento da complexidade das atividades e ações que envolvem todo o projeto em questão. Nem sempre os envolvidos terão condição e capacidade para resolver todos os problemas que aparecem ao longo do caminho. Nesse sentido, faz-se necessário contar / planejar para que a equipe seja multidisciplinar, para superar os desafios e dar conta de encontrar soluções que ultrapassem as áreas de Design e a da Dança.

Outro aspecto que merece destaque é a baixa autoestima dos catadores, que, de certa forma, comprometeu os resultados do projeto. É preciso trabalhar mais esse aspecto em projetos futuros. 
Em relação à aprendizagem, Lave e Wenger (1991) argumentam que ela está em toda parte e não depende de um local específico para que ocorra. Nesse sentido, foi possível perceber no dia a dia o quanto houve de aprendizagem para todos os participantes: professores, alunos e catadores. A troca de experiências e de saberes foi um dos principais ganhos que fizeram parte deste projeto.

Embora não tenhamos atingido plenamente todas as metas do projeto, o que fizemos desenvolvimento dos produtos e implantação do site para a associação e das oficinas de dança tem feito a diferença no cotidiano dos catadores, contribuindo para a melhoria de sua autoestima e a qualidade de vida. Até o momento de finalização deste artigo, a informação que tivemos era de que o site tem dado mais visibilidade para a associação, proporcionado aumento significativo na quantidade de doações de materiais e, sobretudo, demostrado para as pessoas a contribuição que a Asmare tem dado ao meio ambiente e à sociedade.

O projeto foi premiado na "Semana do Conhecimento UFMG - 2016" como destaque de atividade de extensão na categoria "Trabalho e renda". Além disso, gerou algumas matérias jornalísticas, por exemplo: no Boletim UFMG ${ }^{5}$, na TV UFMG ${ }^{6}$ e na Rádio UFMG Educativa ${ }^{7}$, em comemoração aos 90 anos da UFMG. Toda essa divulgação, além do reconhecimento relacionado às atividades do projeto, tem contribuído para dar mais visibilidade à Asmare, uma associação negligenciada pelo Poder Público, que merece todo o nosso reconhecimento e, principalmente nossa contribuição para que continue funcionando de modo eficiente e duradouro.

\section{Considerações finais}

Nesta última parte apresentamos algumas reflexões sobre a experiência com os projetos aqui apresentados relacionadas às seguintes diretrizes de extensão: Interação Dialógica, Interdisciplinariedade, Indissociabilidade entre Ensino, Pesquisa e Extensão, Impacto na Formação do Estudante e Impacto e Transformação Social. ${ }^{8}$

Em relação à Interação Dialógica, durante a construção das propostas, bem como ao longo do desenvolvimento dos projetos, a relação que permeou nossas atividades foi fundamentada no diálogo com todos os envolvidos (catadores, alunos, professores) e na troca de saberes. Essa relação horizontal proporcionou voz ativa a todos os participantes.

A propósito da Interdisciplinariedade, embora a área do Design seja interdisciplinar por natureza, para a maioria das atividades existe a necessidade de interação ou integração com outras áreas de conhecimento. Percebemos que houve pouco avanço quanto às ações de design nas atividades do projeto. Assim, concluímos que é necessária a integração com outras disciplinas para que possamos dar conta da complexidade relacionada aos grupos envolvidos. Nesta última fase do projeto, 2017-2018, pudemos perceber o ganho que tivemos com a inclusão da área da Dança para tentar transpor dois dos principais obstáculos do projeto: a baixa autoestima e a

\footnotetext{
${ }^{5}$ Ver: <https://www.ufmg.br/boletim/bol1976/6.shtml>.

${ }^{6}$ Ver: <https://www.ufmg.br/online/arquivos/047471.shtml>.

${ }^{7}$ Ver: <https://ufmg.br/comunicacao/noticias/radio-veicula-pilulas-sonoras-com-curiosidades-sobre-a-ufmg>.

8 Diretrizes de extensão segundo a Politica Nacional de Extensão Universitária (PNEU). Disponível em: <https://www.ufmg.br/proex/renex/images/documentos/Pol\%C3\%ADtica-Nacional-de-Extens\%C3\%A3oUniversit\%C3\%A1ria-e-book.pdf>.
} 
participação efetiva dos associados nas atividades.

Em relação às diretrizes de Indissociabilidade entre Ensino, Pesquisa e Extensão e Impacto na Formação do Estudante, ficou evidente a riqueza de oportunidades com as quais os alunos envolvidos com esses projetos puderam aprender, experimentar, trocar saberes e conhecimentos. Além disso, percebeu-se facilmente o amadurecimento dos alunos participantes. Com as atividades dos projetos de extensão, eles puderam colocar em prática o que aprendiam na escola, sobretudo porque experimentaram situações e condições que somente acontecem nas interações durante o projeto.

Podemos perceber o impacto dessas ações de Extensão na vida dos alunos por meio de alguns depoimentos:

É um grande privilégio ter essa imersão que possibilita entender cada vez mais o amplo campo de atuação e aplicação do conceito de Design Social através de um projeto tão complexo e desafiador - Mércia Guilherme (bolsista, aluna do Curso de Design).

Projetos como este se apresentam como oportunidade única na vida de um aluno, que pode pôr em prática todo o conhecimento teórico adquirido em sala e mostrar que o Design é social e que podemos ir além. Nos faz refletirmos sobre nossas responsabilidades profissionais e sociais - Kery Silva (voluntária, aluna do Curso de Design).

O projeto Catadores de Sonhos tem sido de imensa importância para a ampliação da minha visão sobre os papéis que profissionais da nossa área podem desempenhar em diferentes campos de atuação, além de destacar o impacto positivo que podemos ter na sociedade - Izabela Costa de Oliveira Barra (bolsista, aluna do Curso de Design).

Tem sido uma experiência incrível, de troca e aprendizagem constante, além de ser uma oportunidade de oferecer uma perspectiva diferente da arte e da dança para pessoas que geralmente não têm acesso a essa realidade, o que é extremamente gratificante - Ana Paula Lima Magalhães (bolsista, aluna do Curso de Dança).

Para ilustrar como essa experiência foi rica, citamos mais dois depoimentos dos técnicos que trabalharam na Asmare e que muito contribuíram para o início dessa parceria, o artista plástico Maurício Melo e a assistente social Flávia Gonzaga.

Maurício:

Os projetos desenvolvidos pelos alunos foram inusitados e com absoluta pertinência entre briefing e produto. Das dificuldades, os alunos fizeram parâmetros ou desafios. Uns foram respeitados, outros foram superados... $\mathrm{E}$, ao final, nada se perdeu no conceito ou no valor estético e funcional das propostas geradas. Não fosse todo esse inventário prático, ainda tivemos o ganho social. A interação entre mundos aparentemente tão distantes trouxe ganhos memoráveis para todos. A troca de experiências e conhecimentos foi regada com grandes doses de generosidade.

Flávia:

O projeto inseriu novas tecnologias sociais, com o propósito de agregar valor ao trabalho da Asmare, por meio da capacitação dos trabalhadores e desenvolvimento de produtos, na perspectiva não somente da sustentabilidade ambiental mas também por meio de grandes transformações nas relações sociais dos catadores com a cidade. Apesar do importante trabalho ofertado para a comunidade, esses atores ainda são marginalizados, e não são respeitados como trabalhadores.

Em relação à última diretriz, Impacto e Transformação Social, pode-se afirmar que foi uma 
via de mão dupla. As ações dos projetos geraram impactos de dentro da universidade para fora, bem como do grupo externo envolvido (de fora) para dentro da universidade. A transformação social abarcou todos os envolvidos: catadores, alunos e professores. A cada novo projeto de Extensão (dentre os apresentados aqui), parecia que estávamos começando tudo de novo. De fato, estávamos, mas cada (re)começo era diferente. Com cada um dos projetos, aprendemos um pouco mais sobre as pessoas, sobre a associação, sobre nós mesmos e sobre a universidade. Em cada projeto, havia um tipo de relação com a associação. Por exemplo, ao longo desses anos lidamos com três diretorias diferentes. Outro aspecto é que alguns alunos participaram de mais de uma fase do projeto, mas, de maneira geral, houve sempre novos alunos envolvidos a cada ano, e isso também tornava tudo diferente.

Para finalizar, mais duas reflexões. A primeira se relaciona com as dificuldades para se realizar atividades de Extensão. Isso não é novidade para quem as realiza, mas pode ser importante explicitar e refletir sobre elas. Alguns aspectos são importantes para essas reflexões. $O$ primeiro tem a ver com a necessidade de sairmos da tal "zona de conforto". Quando nos envolvemos com ações de Extensão desse tipo, estamos lidando com problemas reais de determinado grupo ou instituição. Assim, ao assumir um projeto, estamos nos comprometendo com o grupo, e esse comprometimento nos tira do lugar comum e sempre nos lança desafios. $\mathrm{O}$ segundo tem a ver com o tempo no qual as atividades são realizadas. Como são muitos os envolvidos, nem sempre (ou quase nunca) o andamento do projeto ocorre como planejamos. Na prática, as ações e atividades são bem mais complexas do que poderíamos imaginar. Terceiro, é muito difícil de lidar com grupos, pois isso significa compartilhar decisões, construir caminhos juntos e buscar alternativas que atendam a todos. São muitos os interesses em jogo, muitas negociações e as decisões têm de atender ao interesse coletivo. Por fim, a dificuldade de se fazer a gestão financeira dos projetos. Lidar com a burocracia, com as questões orçamentárias, com o sistema de compras e com os prazos para aplicar os recursos foi algo bastante complexo.

Apesar dessas dificuldades, vale a pena realizar atividades de Extensão. Além, claro, da importância para a sociedade e para a universidade. Primeiro, porque estamos numa instituição pública, e por isso temos o dever de dar algum tipo de retorno para a sociedade, que pode ocorrer de várias maneiras, e a ação de Extensão é apenas um exemplo. Segundo, porque faz bem saber que nossas ações fizeram diferença para a vida de algumas pessoas e que conseguimos diminuir, um pouco que seja seu sofrimento. Elas muito contribuíram, e contribuem, para a sociedade, mas não têm tido o reconhecimento nem mesmo o respeito que merecem por parte de muitas pessoas e até do Poder Público.

A segunda reflexão tem a ver com a desproporcionalidade relacionada ao tempo e ao trabalho despendido versus a situação precária na qual a associação se encontra. Explicamos: temos consciência de que fizemos muita coisa. Foram anos de trabalho e de participação de muitos alunos, além de muitos recursos aplicados pelo MEC e pela Proex-UFMG e de muitas horas de trabalho. Olhando para a Asmare, nesse caso, fica a impressão de que o que fizemos foi pouco se compararmos como a associação estava há cinco anos. É claro que muitas coisas realizadas não podem ser mensuradas para que saibamos o quanto foi ou não suficiente ou, mesmo, o quanto melhorou. É uma situação curiosa saber que trabalhamos tanto ao longo desses anos e que, mesmo assim, a associação parecer estar quase do mesmo jeito que a encontramos. Cabe esclarecer que nem tudo depende desse tipo de ação. Os problemas cotidianos são bem mais complexos - por exemplo, o descaso do Poder Público com a prestação de serviço da Asmare. Esse 
aspecto mostra o quanto a nossa política de construção de cidadania precisa evoluir e envolver os diversos setores da sociedade. Nosso desejo é o de que a associação estivesse melhor e com menos dificuldades para dar continuidade ao seu importante trabalho.

Entendemos, neste ponto da nossa história, que fizemos bastante, mas ainda há muito a ser feito. No momento de finalização deste artigo, estávamos justamente buscando alternativas para os percalços encontrados para as atividades de continuidade. E, assim, mais uma vez, permanecíamos lidando com um dos aspectos mais fascinantes do Design e da Dança: lidar com a falta de controle do processo e com o imprevisto, os quais geram aprendizado e bons resultados para aqueles que estão sempre atentos às surpresas que a vida nos oferece.

\section{Referências}

CORRÊA, Glaucinei Rodrigues; MOURA, Karine Nieman Botelho; PEREIRA, Wilton Duarte. Contribuição do design para o desenvolvimento social de catadores de materiais recicláveis. In: Colóquio Internacional de Design, Escola de Design da Universidade do Estado de Minas Gerais, Belo Horizonte, 2015.

CORRÊA, Glaucinei Rodrigues; SARMIENTO, Jameny; PEREIRA, Wilton Duarte. Contribuições do design para o bem-estar social. In: Estudos em Design (on line), v. 5, p. 170-193, 2017.

FREIRE, Paulo. Pedagogia da autonomia. Rio de Janeiro: Paz e Terra, 1996, Ano da Digitalização: 2002.

GÉLY, Raphaël. Entre immobilité, pesanteur et mouvement: la danse originaire du corps. Straus, Maldiney, Merleau-Pont. Disponível em:

<https://www.academia.edu/7977631/Entre_immobilité_pesanteur_et_mouvement_la_danse_or iginaire_du_corps._Straus_Maldiney_Merleau-Ponty>. Acesso em 09 de agosto de 2014.

GODARD Hubert. Le geste et sa perception. Postface. In: La Danse au XX ème siècle, 2002.

LAVE, Jean; PACKER, Martin. Towards a social ontology of learning. In: NIELSEN, K. et al. A qualitative stance: essays in honor of Steinar Kvale. Oxford: Aarhus Universitetsforlag, 2008.

LAVE, Jean; WENGER, Etienne. Situated learning: legitimate peripheral participation. New York: Cambridge University Press, 1991.

LOUPPE, Laurence. Poétique de la danse contemporaine. Bruxelles: Contredanse, 2004.

RANCIÈRE, Jacques. Le maître ignorant. Paris: Collection Fait et cause - édition Faillard, 1987.

STRAUSS, Erwin. Les formes du spatial, leur signification pour la motricité et la perception. Traduction Michèle GENNARD. In: Figures de la Subjectivité, Éditions du CNRS, Paris, 1992.

THIOLLENT, M. Metodologia da Pesquisa-Ação. São Paulo: Cortez, 1986. 